\title{
Inovação na Indústria Sucroalcooleira Paulista: Os Determinantes da Adoção das Tecnologias de Agricultura de Precisão
}

\author{
Claudia Brito Silva Cirani ${ }^{1}$ \\ Márcia Azanha Ferraz Dias de Moraes ${ }^{2}$
}

\begin{abstract}
Resumo: As tecnologias de Agricultura de Precisão (AP) já são adotadas nas lavouras do Brasil, com técnicas cada vez mais produtivas, indispensáveis para garantir a liderança do País na produção agrícola. No entanto, ainda não existem estudos sobre a intensidade do uso das tecnologias de AP no País e dos condicionantes de sua adoção. O desafio central deste trabalho foi, então, investigar o processo de adoção e uso das tecnologias de AP alcançado pela indústria sucroalcooleira no estado de São Paulo. Para tanto, foram utilizados dados primários, a partir de encaminhamento de questionário a todas as empresas do setor sucroalcooleiro paulista, com o objetivo de conhecer não só o grau de adoção e uso das tecnologias de AP, mas também de verificar a influência das variáveis estudadas na probabilidade de adoção dessas tecnologias. As conclusões deste trabalho sugerem não apenas que o percentual de adoção das tecnologias de AP é elevado na indústria sucroalcooleira paulista, mas também que a probabilidade de adotar tais tecnologias é maior em ordem decrescente de importância, em usinas/destilarias de capital nacional, que fazem parte de um grupo empresarial, de orientação exportadora, de gestão profissional, e que utilizam maior percentual de recursos próprios para investimentos na empresa.
\end{abstract}

Palavras-chaves: agricultura de precisão, modelo lógite, cana-de-açúcar.

\footnotetext{
${ }^{1}$ Doutora em Economia Aplicada pela Escola Superior de Agricultura "Luiz de Queiroz"ESALQ/USP. E-mail:cloubrito@hotmail.com

${ }^{2}$ Professora doutora da Escola Superior de Agricultura "Luiz de Queiroz"- ESALQ/USP.

E-mail:mafdmora@esalq.usp.br.
} 
544 - Inovação na Indústria Sucroalcooleira Paulista: Os Determinantes da Adoção das Tecnologias de Agricultura de Precisão

Abstract: Technologies of Precision Agriculture (PA) are already a reality in crops throughout Brazil, using more and more productive techniques, crucial to ensure the country as the world leader in agriculture. However, studies on the intensity of the use of PA technologies in Brazil and the determiners of their adoption do not exist yet. The main focus of this study was, therefore, to investigate the adoption process and the use of PA technologies in the sugarcane industry in São Paulo state. For that purpose, it used primary data based upon a questionnaire submitted to all enterprises of the sugarcane sector in the state, aiming to figure out not only the adoption level and use of PA technologies in the sugarcane industry, but also to verify the influence of the variables studied on the probability for the adoption of the PA technologies. The conclusions of this study suggest that the percentage for the PA adoption is high in the sugarcane industry of São Paulo and also that the probability to adopt PA technologies is higher in decrescent order of importance in mills/distilleries of national capital, which are part of an export-driven group, of professional management and that use higher percentage of their own resources.

Key-words: precision agriculture, logit model, sugarcane.

Classificação JEL: Q1, Q16.

\section{Introdução}

A literatura recente aponta que o desenvolvimento e a difusão de novas tecnologias são essenciais para crescimento da produção e aumento da produtividade (OCDE, 1997). O mercado globalizado exige das empresas reestruturação para enfrentar a abertura da economia, engajando-se em processos de racionalização, inserção internacional e inovação - recursos internos que possibilitaram a transformação da indústria brasileira em uma das maiores e mais diversificadas entre os países em desenvolvimento, apesar de seu processo de inovação ser ainda deficiente. Sem dúvida que a inserção internacional mais dinâmica e competitiva da indústria nacional só pode ser obtida por meio da adoção de novas tecnologias. Portanto, pode-se afirmar que a inovação tecnológica é o elemento-chave para a indústria enfrentar a abertura da economia e buscar a melhor inserção no mercado mundial.

Grande parte das inovações tecnológicas introduzidas na agricultura constitui-se de máquinas, equipamentos, defensivos agrícolas, fertilizantes químicos e outros produtos que são, na verdade, biotecnologias e novos produtos 


\section{Claudia Brito Silva Cirani

industriais utilizados pelo setor agroindustrial. Esse setor caracteriza-se, cada vez mais, pela globalização dos mercados, pelo crescente uso de novas tecnologias e pela busca da produção sustentável. Tal realidade obriga o setor agroindustrial brasileiro a adotar novas tecnologias, empregando-as a fim de elevar sua produtividade, melhorar seus produtos e métodos de gestão e contribuir para a preservação do meio ambiente e, consequentemente, possibilitar maior competitividade no mercado mundial. Sem dúvida que essa realidade demanda da agroindústria uma atuação empresarial que visa atar dois lados, ou seja, otimizar os sistemas produtivos e minimizar o impacto ambiental. No enfrentamento desse desafio, a empresa agrícola busca novas tecnologias, tais como a Agricultura de Precisão (AP), para que, ao empregá-las, possa promover a redução de custo e a preservação ambiental ${ }^{3}$.

$\mathrm{O}$ foco da AP é o gerenciamento da variabilidade espacial da produção e dos fatores nela envolvidos, realizada por meio de tecnologias recentes adaptadas para o meio agrícola, com o objetivo de possibilitar a redução do uso de insumos e do impacto sobre o meio ambiente.

A AP, na atualidade, ganha uma definição mais sistêmica, podendo ser definida como uma nova forma de gestão ou de gerenciamento da produção agrícola, e não apenas como um conjunto de ferramentas para o tratamento localizado da lavoura. É um elenco de tecnologias e procedimentos utilizados para que as lavouras e os sistemas de produção sejam otimizados, tendo como elemento-chave o gerenciamento da variabilidade dos fatores de produção (SWINTON; DEBOER, 1998).

O setor sucroalcooleiro vem investindo fortemente nessas tecnologias. Estimativas informais apontam que $10 \%$ da área de cana-de-açúcar vem sendo cultivada com AP, especificamente a tecnologia de aplicação em taxa variada ${ }^{4}$. Muitas ainda estão em desenvolvimento, como a aplicação localizada de defensivos e o mapeamento da produtividade (MOLIN, 2001), e outras estão em plena adoção, como por exemplo, a utilização de distribuidores de fertilizantes e corretivos que fazem a regulagem e a dosagem automaticamente, de acordo com a necessidade ou recomendação para cada local do campo (BAIO, 2006).

Outra tecnologia de AP cada vez mais utilizada na cultura da cana é o piloto automático. Os maquinários são direcionados automaticamente sobre

\footnotetext{
3 As tecnologias de AP envolvem um conjunto de ferramentas, tais como o GPS (Sistema de Posicionamento Global); monitor de colheita; tecnologia de aplicação em taxa variada; sistema de direcionamento via satélite por barra de luz; autodirecionamento ou piloto automático; entre outras.

4 Esta estimativa foi apontada por especialistas no Congresso Brasileiro de Agricultura de Precisão - Conbap, 2008, Piracicaba.
} 
546 - Inovação na Indústria Sucroalcooleira Paulista: Os Determinantes da Adoção das Tecnologias de Agricultura de Precisão

uma linha planejada de aplicação, por meio do direcionamento automático do comando da direção, sem requerer nenhum esforço do operador. Essa tecnologia apresenta uma série de vantagens, tais como permitir a redução da compactação do solo por meio do controle do tráfego; permitir também velocidades operacionais maiores; reduzir a fadiga do operador; permitir a operação mesmo com falta de visibilidade; otimizar o raio de manobras; minimizar erros de faixa; aumentar o rendimento operacional; permitir a redução do consumo de combustível; entre outras.

O Brasil é hoje o maior produtor de cana-de-açúcar do mundo. O estado de São Paulo é responsável por 60\% de toda a produção nacional (UNICA, 2008a), sendo o interior paulista a principal região produtora do Brasil, caracterizando-se pelo seu sistema mecanizado de produção canavieiro, com destaque para a utilização da AP.

É indiscutível que a adoção da AP tem como exigência o dinamismo do processo de inovação tecnológica na indústria sucroalcooleira, visando a aumentar a produtividade, melhorar a qualidade da cana, reduzir os custos de produção e o impacto sobre o meio ambiente. Apesar de a AP ser uma importante ferramenta para otimização dos sistemas produtivos e minimização do impacto ambiental e também de já estar presente em algumas atividades agrícolas brasileiras, ainda não existem estudos sobre o grau de sua adoção no país e de seus condicionantes.

Este estudo propõe, então, mensurar o grau de adoção e uso das tecnologias de $\mathrm{AP}$, verificando quais as tecnologias que têm sido mais utilizadas e, além disso, identificar os principais fatores que determinam sua adoção e uso na indústria sucroalcooleira no estado de São Paulo.

Este trabalho divide-se em cinco seções, incluindo a introdução. As referências bibliográficas são apresentadas na seção 2 . A seção 3 descreve a metodologia adotada. A seção 4 quantifica a intensidade do uso das tecnologias de AP nas empresas sucroalcooleiras do estado de São Paulo. Em seguida, identificam, por meio de um modelo lógite, os principais fatores que determinam a adoção e uso dessas tecnologias na indústria sucroalcooleira paulista. Por fim, a seção 5 traz as considerações finais, seguida da bibliografia.

\section{Levantamento bibliográfico}

A análise do processo de difusão e adoção de novas tecnologias ganha, a cada dia, destaque na literatura econômica. Diferentes escolas do pensamento vêm desenvolvendo teorias que explicam os motivos pelos quais as empresas inovam. 


\section{Claudia Brito Silva Cirani \& Márcia Azanha Ferraz Dias de Moraes}

Das ideias de Joseph Schumpeter, surge a Economia da Inovação, que está no cerne da mudança econômica. Para o autor, as inovações radicais provocam grandes mudanças no mundo, enquanto as inovações incrementais preenchem continuamente o processo de mudança (SCHUMPETER, 1982). O livro “Teoria do Desenvolvimento Econômico", publicado em 1912, aborda a existência de vários tipos de inovações, tais como: introdução de um novo produto ou mudança qualitativa de um produtojá existente; inovação de processo novo para a empresa; abertura de um novo mercado; desenvolvimento de novas fontes de matérias-primas; mudanças na organização da indústria etc.

Nos anos 1980, a teoria de Hayami e Ruttan propôs que a inovação tecnológica fosse induzida pela dotação de fatores, dada historicamente, de tal maneira que $o$ fator relativamente escasso fosse poupado $\mathrm{o}$ fator relativamente abundante, usado intensivamente. Como exemplo, os autores citam os Estados Unidos, onde as inovações foram do tipo mecânico, em que o uso da mão de obra era poupado, pois trata-se do fator escasso quando comparado à terra. No Japão, contudo, as inovações foram químicas, por ter como fator escasso a terra, ao contrário da mão de obra, que era abundante (HAYAMI; RUTTAN, 1988).

No modelo de Hayami e Ruttan, a experiência histórica demonstra que quando a mão de obra se torna escassa, produtores e demais forças econômicas e políticas pressionam as instituições de pesquisa para priorizar o desenvolvimento de tecnologias de natureza mecânica, economizadoras de mão de obra. Por outro lado, quando a terra se torna escassa, o esforço dos centros de pesquisa se concentra na criação de tecnologias predominantemente de natureza biológica.

Segundo a teoria da inovação induzida, esse processo de identificação das oportunidades tecnológicas desempenha papel fundamental para a existência de um sistema eficiente de informações entre os atores (produtores, universidades, instituições públicas de pesquisa, serviços tecnológicos, indústria e empresários).

Além da suposta escassez de mão de obra ou abundância de terra, outras teorias são formuladas para explicar o motivo que leva empresas a buscarem a inovação. A razão apresentada por Schumpeter (1982) é que, se elas estão em busca de lucros, um novo dispositivo tecnológico leva sempre à alguma vantagem para o inovador. Para ele, as empresas inovam para defender suas posições competitivas ou por buscarem vantagem competitiva.

Além disso, cada vez mais se entende que a difusão tecnológica apresenta outras características, como por exemplo, a influência sobre as dinâmicas de mercado que as afastam do equilíbrio. Tal constatação resultou no 
548 - Inovação na Indústria Sucroalcooleira Paulista: Os Determinantes da Adoção das Tecnologias de Agricultura de Precisão

desenvolvimento mais recente da Economia Evolucionária. Os principais expoentes dessa abordagem, Nelson e Winter (1982), acompanhados por outros participantes da corrente evolucionária neoschumpeteriana, além de seguirem as principais ideias de Schumpeter sobre a dinâmica da inovação, propõem romper com os pressupostos metodológicos tradicionais de equilíbrio, substituído pela noção mais geral de trajetória, e de racionalidade maximizadora, substituída pela racionalidade limitada ou processual.

A abordagem evolucionária proposta por Nelson e Winter (1982) baseiase na interação temporal entre as estratégias empresariais, que envolvem o referido processo de busca de inovações e o processo de seleção, pelo mercado, dessas mesmas inovações. Assim, o principal objeto de análise é a evolução temporal da indústria, em que se vai modificando endogenamente, por meio das inovações e de sua seleção pelo mercado. Portanto, a perspectiva teórica evolucionária procura caracterizar o processo inovador a partir da busca e da seleção de inovações.

Os canais e redes, por meio dos quais informações, conhecimentos, ideias e capacidades circulam, são fortemente guiados e restringidos pela estrutura institucional em que a empresa está situada, como por exemplo, universidades, institutos públicos de pesquisa e agências públicas e privadas de fomento ao investimento em inovação. Lundvall (1992) denominou "Sistemas Nacionais de Inovação" esse conjunto de instituições que contribui para inovação e fluxos de conhecimento.

A partir do início da década de 90, ampliou-se o entendimento do processo de inovação com a elaboração do Manual de Oslo, pela OCDE (Organização para Cooperação e Desenvolvimento Econômico) e a Comissão Européia, cujo objetivo é servir como orientação para coleta de dados sobre inovação tecnológica. O manual serve até hoje como referência para todas as tentativas de mensuração dos processos de inovação.

No caso da difusão das tecnologias de agricultura de precisão, a rapidez do uso dessas técnicas resulta na necessidade de conduzir estudos de caráter eminentemente empírico, baseados nas análises quantitativas. A especificidade de pesquisas realizadas nos Estados Unidos serviu de base para este trabalho, visto que ainda não existem estudos desta natureza sobre o Brasil.

Ressalta-se que, em âmbito internacional, estudos sobre determinantes da adoção das tecnologias de AP são relativamente escassos. Como fontes de pesquisa, serão citados neste estudo quatro artigos publicados nos Estados Unidos neste início de milênio, entre 2000 e 2004, que servem de base para as análises realizadas: Sevier e Lee (2004); McBride e Daberkow (2003); Batte e Arnholt (2002); eEnglish, Roberts e Larson (2000). A seguir, um resumo dos quatro artigos. 
Quadro 1. Evidências internacionais sobre os determinantes da adoção das tecnologias de AP

\begin{tabular}{|c|c|c|c|}
\hline Artigo & País/Amostra/Ano & Metodologia & Resultados \\
\hline $\begin{array}{l}\text { Sevier e Lee } \\
(2004)\end{array}$ & $\begin{array}{l}\text { - Estados Unidos } \\
\text { - } 10 \text { principais } \\
\text { municípios produtores } \\
\text { de laranja na Flórida } \\
\text { - Sevier and Lee (2003) }\end{array}$ & $\begin{array}{l}\text { - Coleta de dados: aplicação de } \\
\text { questionários via correio } \\
\text { - Modelo próbite tendo como variável } \\
\text { dependente a adoção ou não das } \\
\text { tecnologias de AP. As variáveis } \\
\text { explicativas utilizadas foram: área } \\
\text { da propriedade; idade, experiência } \\
\text { e escolaridade dos produtores e } \\
\text { variabilidade da produção }\end{array}$ & $\begin{array}{l}\text { - Os resultados dos modelos } \\
\text { econométricos indicaram que as } \\
\text { variáveis variabilidade da } \\
\text { produção, idade do produtor e } \\
\text { área da propriedade têm relação } \\
\text { positiva e significativa com a } \\
\text { probabilidade de adoção das } \\
\text { tecnologias de AP na cultura de } \\
\text { laranja }\end{array}$ \\
\hline $\begin{array}{l}\text { McBride e } \\
\text { Daberkow } \\
(2003)\end{array}$ & $\begin{array}{l}\text { - Estados Unidos } \\
\text { - } 3200 \text { produtores de } \\
\text { milho e soja } \\
\text { - } 1998\end{array}$ & $\begin{array}{l}\text { - Dados do USDA (United States } \\
\text { Department of Agriculture) } \mathrm{e} \\
\text { Agricultural Resource Management } \\
\text { Survey (ARMS) } \\
\text { - } 3 \text { modelos lógites para o produtor } \\
\text { que: i) tenha conhecimento sobre } \\
\text { AP; ii) utiliza AP para o } \\
\text { diagnóstico; e iii) utiliza AP para a } \\
\text { correção. As variáveis explicativas } \\
\text { referiram-se às características da } \\
\text { propriedade e do produtor e às } \\
\text { fontes de informação para adoção } \\
\text { das tecnologias de AP }\end{array}$ & $\begin{array}{l}\text { - Os resultados indicaram que as } \\
\text { empresas de consultoria e os } \\
\text { fornecedores de insumos foram } \\
\text { as principais fontes de } \\
\text { informação para adoção das } \\
\text { tecnologias de AP } \\
\text { - Além disso, a mídia e o setor } \\
\text { privado são fatores importantes } \\
\text { para a difusão das tecnologias de } \\
\text { AP }\end{array}$ \\
\hline $\begin{array}{l}\text { Batte e } \\
\text { Arnholt } \\
(2002)\end{array}$ & $\begin{array}{l}\text { - Estados Unidos } \\
\text { - Cooperativa de } \\
\text { produtores em Ohio } \\
\text { com } 325 \text { produtores } \\
\text { rurais } \\
\text { - } 2001\end{array}$ & $\begin{array}{l}\text { - Coleta de dados: questionários } \\
\text { aplicados pelo correio } \\
\text { - Modelo próbite cuja variável } \\
\text { dependente é baseada na pergunta: } \\
\text { os benefícios têm excedido os } \\
\text { custos com a adoção das } \\
\text { tecnologias de AP? As variáveis } \\
\text { independentes foram: área da } \\
\text { propriedade; produtores cuja } \\
\text { ocupação não se restringe apenas à } \\
\text { área agrícola; experiência; } \\
\text { variabilidade da produção; } \\
\text { presença de monitor de colheita e } \\
\text { do GPS }\end{array}$ & $\begin{array}{l}\text { - Os resultados mostraram que a } \\
\text { probabilidade de obter } \\
\text { lucratividade com a adoção do } \\
\text { monitor de colheita é possível } \\
\text { apenas com o uso do GPS. Ou } \\
\text { seja, a percepção dos produtores } \\
\text { com relação aos benefícios } \\
\text { econômicos da AP está associada } \\
\text { positivamente à adoção do } \\
\text { monitor de colheita em conjunto } \\
\text { com o GPS }\end{array}$ \\
\hline
\end{tabular}

RESR, Piracicaba, SP, vol. 48, no 4, p. 543-565, out/dez 2010 - Impressa em Março 2011 
550 - Inovação na Indústria Sucroalcooleira Paulista: Os Determinantes da Adoção das Tecnologias de Agricultura de Precisão

\begin{tabular}{|c|c|c|c|}
\hline $\begin{array}{l}\text { English, } \\
\text { Roberts e } \\
\text { Larson (2000) }\end{array}$ & $\begin{array}{l}\text { - Estados Unidos } \\
\text { - Surveys do County } \\
\text { Agricultural Extension } \\
\text { Agents realizados em } 95 \\
\text { municípios do } \\
\text { Tennessee e Census of } \\
\text { Agriculture } \\
\text { - } 1999\end{array}$ & $\begin{array}{l}\text { - Coleta de dados: entrevistas } \\
\text { telefônicas em } 95 \text { municípios do } \\
\text { Tennessee } \\
\text { - Regressões logísticas para estimar a } \\
\text { probabilidade de adoção de quatro } \\
\text { tecnologias de AP por produtores } \\
\text { dos municípios de Tennessee. As } \\
\text { variáveis explicativas empregadas } \\
\text { foram: área da propriedade; } \\
\text { rentabilidade; número de } \\
\text { trabalhadores proprietários, sócios } \\
\text { ou arrendatários das terras } \\
\text { cultivadas }\end{array}$ & $\begin{array}{l}\text { - Os resultados serviram de } \\
\text { subsídios às agroindústrias na } \\
\text { escolha da região mais adequada } \\
\text { para a implantação da AP } \\
\text { - A adoção das tecnologias de AP } \\
\text { está positivamente } \\
\text { correlacionada aos municípios } \\
\text { com características favoráveis, } \\
\text { como por exemplo, municípios } \\
\text { com propriedades de grande } \\
\text { porte e com terras disponíveis } \\
\text { para o cultivo }\end{array}$ \\
\hline
\end{tabular}

\section{Metodologia}

\subsection{Modelo econométrico}

O procedimento econométrico utilizado neste trabalho foi o modelo lógite, cuja variável dependente é binária, isto é, uma variável que indica a ocorrência ou não de um evento, ou presença ou ausência de uma condição. O modelo aqui utilizado teve como finalidade modelar a adoção da AP na indústria sucroalcooleira paulista ${ }^{5}$. Atribui-se, assim, o valor 1 à adoção da $\mathrm{AP}$ e 0 à não adoção. As variáveis explicativas são representadas pelo vetor $\mathbf{x}$ que explica a decisão entre adotar ou não:

$$
\operatorname{Pr}(y=1)=F\left(\boldsymbol{\beta}^{\prime} \mathbf{x}_{\mathbf{i}}\right) \rightarrow \text { probabilidade de uma empresa com determinadas }
$$
características $\mathbf{x}$ adotar a $\mathrm{AP}$

$\operatorname{Pr}(y=0)=1-F\left(\boldsymbol{\beta}^{\prime} \mathbf{x}_{i}\right)$

Os parâmetros $\boldsymbol{\beta}$ refletem o impacto das mudanças de $\mathbf{x}$ na probabilidade de adoção da AP na indústria sucroalcooleira paulista.

\footnotetext{
5 Para simplificar, de agora em diante, só será utilizado o termo AP para se referir às tecnologias de AP.
} 
O modelo de probabilidade é uma regressão representada por:

$$
E[y \mid \mathbf{x}]=0\left[1-F\left(\boldsymbol{\beta}^{\prime} \mathbf{x}_{\mathbf{i}}\right)\right]+1\left[F\left(\boldsymbol{\beta}^{\prime} \mathbf{x}_{\mathbf{i}}\right)\right]=F\left(\boldsymbol{\beta}^{\prime} \mathbf{x}_{\mathbf{i}}\right)
$$

Se o modelo de probabilidade for linear, ou seja, se $F(\beta \mathrm{x})=\beta$ 'x, dois problemas afetam a sua estimação. Um é o erro heteroscedástico e o outro é o fato de não ser possível restringir as estimativas das probabilidades no intervalo $[0,1]$.

Em modelos com variáveis dependentes binárias não é apropriada a aplicação de métodos de estimação dos parâmetros usuais de regressão, pois pode-se obter valores estimados da variável dependente negativos ou maiores do que 1 incompatíveis com a natureza da variável (HOFFMANN, 2002). Portanto, existem métodos específicos, como os modelos não lineares de probabilidade. Segundo Greene (2003), para que o modelo (3) forneça previsões consistentes espera-se que:

$$
\lim \operatorname{Pr}(y=1)=1
$$

$\boldsymbol{\beta}^{\prime} \mathbf{x} \rightarrow+\infty$

$$
\lim \operatorname{Pr}(y=1)=0
$$

$\boldsymbol{\beta}^{\prime} \mathbf{x} \rightarrow-\infty$

Essas condições serão satisfeitas se $\mathrm{F}$ for uma função de distribuição normal ou logística, entre outras. No modelo lógite, usa-se a função de distribuição logística, que é dada por ${ }^{6}$ :

$$
E[y \mid \mathbf{x}]=\operatorname{Pr}(y=1)=F\left(\boldsymbol{\beta}^{\prime} \mathbf{x}\right)=\frac{e^{\boldsymbol{\beta}^{\prime} \mathbf{x}}}{1+e^{\boldsymbol{\beta}^{\prime} \mathbf{x}}}=\frac{1}{1+e^{-\boldsymbol{\beta}^{\prime} \mathbf{x}}}
$$

\footnotetext{
${ }^{6}$ No modelo próbite utiliza-se a distribuição normal. Os modelos próbite e lógite são semelhantes, exceto nas caudas, que são mais pesadas na distribuição logística. Ou seja, a probabilidade condicional de $\mathrm{P}_{\mathrm{i}}$ se aproxima de 0 ou $1 \mathrm{em}$ um ritmo mais lento no lógite do que no próbite. Dessa forma, não há razões convincentes para preferir um dos modelos ao outro. No entanto, muitos pesquisadores escolhem o modelo lógite por sua relativa simplicidade matemática (GUJARATI, 2006).
} 
552 - Inovação na Indústria Sucroalcooleira Paulista: Os Determinantes da Adoção das Tecnologias de Agricultura de Precisão

No modelo logístico, os parâmetros não são necessariamente os efeitos marginais. Ou seja, como as estimações envolvem funções não lineares, o efeito marginal de uma variável explicativa sobre a variável dependente não é o coeficiente $\boldsymbol{\beta}$, como no modelo linear e, portanto, deve ser calculado para cada caso a fim de possibilitar inferências sobre a influência das variáveis explicativas na probabilidade de $y_{i}=1$. Portanto, para saber o efeito marginal que uma mudança em $\mathbf{x}$ causa na probabilidade de adoção da AP, faz-se:

$$
\frac{\partial E[y \mid \mathbf{x}]}{\partial \mathbf{x}}=\left[\frac{\partial F\left(\boldsymbol{\beta}^{\prime} \mathbf{x}\right)}{\partial\left(\boldsymbol{\beta}^{\prime} \mathbf{x}\right)}\right] \boldsymbol{\beta}=f\left(\boldsymbol{\beta}^{\prime} \mathbf{x}\right) \boldsymbol{\beta}
$$

no qual $F$ é a função de distribuição logística e $f$ é a função densidade de probabilidade.

A estimação dos parâmetros do modelo lógite é feita pelo método de máxima verossimilhança. Cada observação é tratada como sendo retirada de uma distribuição de Bernoulli (ou dicotômica) (GREENE, 2003).

\subsection{Descrição das variáveis selecionadas}

O modelo de regressão logística estimado neste trabalho especifica-se da seguinte forma ${ }^{7}$ :

$A D O_{i}=f(O C, E X, G R, G E, A R E A, C P, A S ; \varepsilon)$

no qual $A D O$ é a variável dependente, sendo $A D O=1$ se a empresa adota $\mathrm{AP} ; A D O=0$ se a empresa não adota. $\mathrm{O}$ termo $\varepsilon$ é o erro aleatório, obedecendo às pressuposições usuais.

As variáveis explicativas foram selecionadas tendo em vista o que se discute na literatura econômica. As variáveis explicativas utilizadas são as seguintes:

a) OC é a origem do capital - variável binária que verifica se a origem do capital é nacional (valor $=1$ ) ou estrangeiro $($ valor $=0$ ). O objetivo dessa variável foi verificar se a origem do capital tem influência sobre

7 Utilizou-se o Software Stata 9.0 para estimação do modelo. 


\section{Claudia Brito Silva Cirani

a probabilidade de adoção da AP. O capital controlador foi classificado em nacional ou estrangeiro. A literatura econômica afirma que o esforço inovativo das empresas de capital nacional é maior do que o das empresas de capital estrangeiro, devido ao fato de a maior parte das atividades de inovação das empresas nacionais ocorrer no País; enquanto que o das estrangeiras é de origem externa e, portanto, menos interativa com o sistema nacional de inovação. Assim, esperase que as empresas de capital nacional sejam mais propensas a adotar $\mathrm{AP}$ em relação às de capital estrangeiro. Ou seja, espera-se um efeito marginal positivo;

b) EXé a orientação exportadora da empresa - variável binária que indica se a empresa exporta (valor $=1$ ) ou não (valor $=0$ ). A exposição da empresa ao mercado internacional incentiva a empresa a investir em novas tecnologias a fim de elevar sua produtividade, melhorar a qualidade de seus produtos e, consequentemente, possibilitar maior competitividade no mercado internacional. Então, espera-se que as empresas que atendem a mercados externos sejam mais propensas a adotar AP. Portanto, espera-se um efeito marginal positivo;

c) GR refere-se ao grupo - variável binária que indica se a empresa é parte de um grupo empresarial (valor $=1$ ) ou se é independente (valor $=0$ ). O efeito marginal esperado é positivo, uma vez que a empresa que faz parte de um grupo pode utilizar-se de outras empresas associadas como canal para o conhecimento dos eventuais benefícios e para a adoção da AP. Isto é, permite um contato com maior número de empresas e, consequentemente, são maiores as chances de adoção da AP. Portanto, espera-se efeito marginal positivo;

d) GE refere-se ao tipo de gestão da empresa - variável binária que indica se a empresa tem gestão profissional (valor $=1$ ) ou familiar (valor $=0$ ). O objetivo dessa variável foi verificar se a gestão empresarial tem influência positiva sobre a probabilidade de adoção de novas tecnologias, isto é, se empresas de gestão profissional são mais propensas a adotar AP do que as familiares. O efeito marginal esperado é positivo;

e) AREA é a área total (própria e arrendada) explorada com a cana-deaçúcar, em hectares. A maioria das tecnologias de AP está dimensionada para grandes áreas. Além disso, o aumento na área explorada permite que a empresa cultive mais áreas com o mesmo conjunto de equipamentos de $\mathrm{AP}$ e, portanto, o custo unitário fica reduzido para grandes áreas. Assim, espera-se um efeito marginal 
554 - Inovação na Indústria Sucroalcooleira Paulista: Os Determinantes da Adoção das Tecnologias de Agricultura de Precisão

positivo, isto é, espera-se que as empresas que possuem maiores áreas exploradas com a cana sejam mais propensas a adotar AP;

f) CP é o percentual de capital próprio da empresa. As fontes de financiamento utilizadas pelas usinas/destilarias foram classificadas em próprias e de terceiros (privado e público). O resultado esperado do efeito marginal é positivo, ou seja, quanto maior o percentual de recursos próprios da empresa, maior será sua disposição para enfrentar riscos e, portanto, maior o investimento em máquinas e equipamentos e, consequentemente, maior a probabilidade de adoção da AP;

g) AS é a associação - variável binária que indica se a indústria sucroalcooleira participa (valor $=1$ ) ou não (valor $=0$ ) de associações do setor ${ }^{8}$. Trata-se de uma variável que captura o grau de conectividade da empresa com outras organizações, em busca da adoção de novas tecnologias. O efeito marginal esperado é positivo, ou seja, a participação em parcerias permite que a empresa tenha contado direto com maior número de pessoas e técnicos especializados. Consequentemente, permite maior contato com as novas tecnologias e conhecimento de seus benefícios, e, portanto, maior a probabilidade de adoção da AP.

\subsection{Dados}

Os dados utilizados neste trabalho foram primários, isto é, obtidos mediante questionários aplicados à indústria sucroalcooleira paulista no segundo semestre de 2008 (entre 19 de agosto e 21 de novembro). A análise inclui todas as usinas/destilarias localizadas no estado de São Paulo que adotam a AP e que não a adotam ${ }^{9}$.

O levantamento das unidades produtoras de açúcar e álcool paulistas foi feito pelo site da Udop (União dos Produtores de Bioenergia), cujo portal na internet fornece uma relação de nomes, endereços, números de telefone e email de todas as usinas/destilarias que se situam no estado.

Para assegurar a qualidade das informações, foram adotados dois procedimentos na fase de coleta dos dados. Primeiro, foi feita a identificação do diretor ou gerente agrícola de cada usina/destilaria, que fosse capaz de apreender

8 Tais como Unica, CTC (Centro de Tecnologia Canavieira), entre outras.

9 Vale ressaltar que os produtores agrícolas independentes não foram considerados neste trabalho, que compreendeu apenas as áreas cultivadas (própria e arrendada) pelas usinas/ destilarias.

11 Nessa estatística, foram usados dados da Unica e, também, deste trabalho. De acordo com 
os conceitos de AP e detivesse as informações requeridas. Importante destacar que a identificação dos diretores ou gerentes da área agrícola foi fundamental neste trabalho por tratar-se de perguntas altamente especializadas, que só podiam ser respondidas por pessoas com autoridade para tomar decisão na empresa e, sobretudo, para passar os dados necessários. A seguir, uma vez identificado o profissional de cada usina/destilaria da amostra, por telefone, foi solicitado o preenchimento do questionário, encaminhado por e-mail. Confirmado o recebimento, foi enviado, também por e-mail, o questionário preenchido.

Durante a coleta dos dados, verificou-se que algumas unidades estão em fase de construção; outras não cultivam cana-de-açúcar (compram toda a cana de fornecedores) e poucas são as que não produzem açúcar e álcool combustível (por exemplo, as destilarias de bebidas e de álcool industrial). Essas usinas/ destilarias foram, portanto, retiradas da contagem da amostra da pesquisa, visto que, na primeira situação, a empresa ainda não está em operação; na segunda, a empresa não exerce atividade agrícola e, na terceira, não exerce atividade no setor sucroalcooleiro. Essa realidade levou a uma amostra consultada de 180 usinas/destilarias. Deve-se salientar que, entre as 180 empresas contatadas, o estudo ateve-se a 87, número obtido a partir dos questionários respondidos. Foi assim que se chegou à abrangência de 87 usinas/destilarias, na constituição do tamanho final da amostra.

\section{Resultados e discussões}

\subsection{Uso das tecnologias de AP}

O índice de respostas obtidas foi satisfatório, uma vez que, num universo de 180 usinas/destilarias consultadas, 87 responderam ao questionário completo da pesquisa referente ao período de 2008, conforme mencionado acima. Isso corresponde a $48 \%$ das empresas sucroalcooleiras paulistas. É importante ressaltar que, juntas, essas empresas foram responsáveis por cerca de $57 \%$ da cana-de-açúcar processada no estado de São Paulo na safra 2007/08 ${ }^{11}$.

a Unica (2008b), o total de cana processada no estado de São Paulo, na safra de 2007/08, foi de 296,3 milhões de toneladas. Segundo os dados deste trabalho, as usinas/destilarias que responderam ao questionário, no total, foram responsáveis por 167,66 milhões de toneladas de cana moída na safra 2007/08. Esse valor representa cerca de 57\% da cana processada no estado de São Paulo.

${ }^{12} \mathrm{O}$ percentual elevado da taxa de adoção das imagens (satélite e fotografias aéreas) pode 
556 - Inovação na Indústria Sucroalcooleira Paulista: Os Determinantes da Adoção das Tecnologias de Agricultura de Precisão

A Tabela 1 apresenta o grau de adoção das usinas/destilarias que adotam $\mathrm{AP}$ e das que não adotam. Conforme pode ser observado, mais de $50 \%$ das empresas adotam AP.

Tabela 1. Empresas que adotam e não adotam AP - estado de São Paulo 2008

\begin{tabular}{lcc}
\hline Empresas & Número de empresas & Percentual \\
\hline Adotam AP & 49 & 56 \\
Não adotam & 38 & 44 \\
\hline
\end{tabular}

Fonte: Dados da pesquisa.

A Figura 1 sintetiza os resultados da taxa de adoção para as diferentes tecnologias de AP. A tecnologia de AP de mais elevada taxa de adoção é a imagem de satélite, que foi de $76 \%{ }^{12}$. Dentre outras tecnologias com elevadas taxas de adoção, destacam-se o piloto automático (39\%), seguido das fotografias aéreas (33\%), amostragem de solo em grade (com GPS) (31\%) e tecnologia de aplicação em taxa variada $(29 \%)^{13}$.

Pode-se verificar também que as tecnologias com as menores taxas de adoção são: sensores e mapeamento da condutividade elétrica do solo (ambas com $0 \%$, isto é, nenhuma usina/destilaria adotou tais tecnologias). Esse fato pode ser um indício da incipiência dessas tecnologias, que não estão perfeitamente adequadas à cultura da cana. Ou seja, podem existir ainda limitações tecnológicas a serem superadas para $\mathrm{o}$ avanço de sua adoção, tais como, problemas de falta de compatibilidade dos aplicativos computacionais usados; necessidade de calibração frequente de sensores, que podem ser afetados por mudanças na topografia e pela presença de impurezas na colheita; e oferta reduzida de oficinas dotadas de equipamentos específicos e de mecânicos especializados.

ser consequência do fato de que a grande maioria dessas imagens não seja especificamente utilizada para AP. Ou seja, as usinas/destilarias, por utilizarem esses recursos, podem considerar isso o suficiente. Esses resultados devem ser, portanto, interpretados com cuidado.

${ }^{13}$ Ressalta-se que os conceitos das tecnologias de AP podem ter sido mal interpretados pelos respondentes. No caso do monitor de colheita e mapeamento, por exemplo, há evidências de que um grupo de usinas/destilarias que considerou o uso da referida tecnologia nos questionários aplicados, não a utilize de fato. Desta forma, essas respostas, em particular, não foram consideradas neste trabalho.

${ }^{14}$ Uma forma de detectar a multicolinearidade é pela análise das correlações parciais entre 


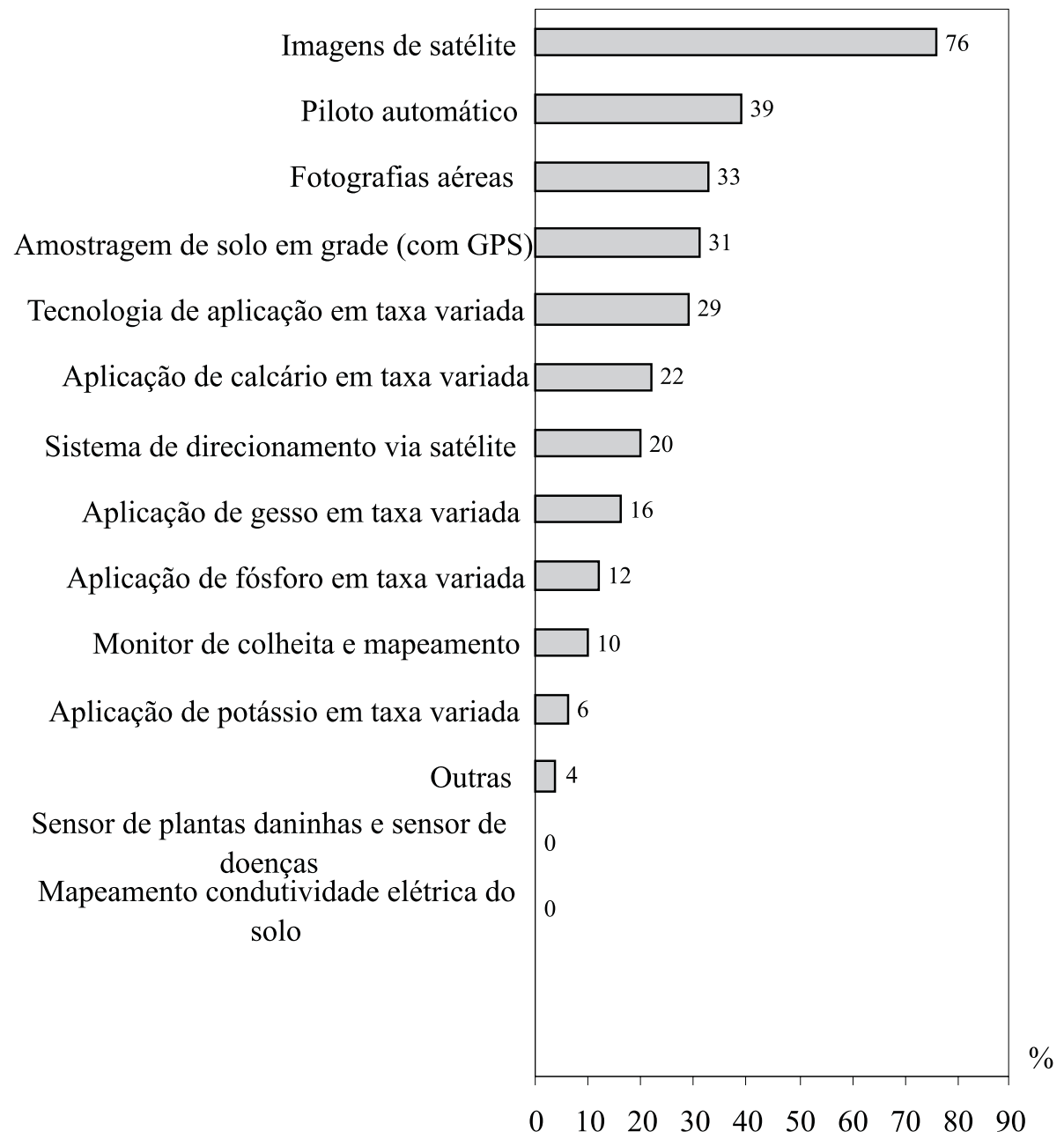

Figura 1. Taxa de adoção da AP, segundo tecnologias de AP - estado de São Paulo-2008

Fonte: Dados da pesquisa.

Com relação a outras tecnologias, $4 \%$ das usinas/destilarias apontaram a aplicação de defensivos em taxa variada que, diferente da aplicação localizada de fertilizantes e corretivos, ainda está em desenvolvimento. 
558 - Inovação na Indústria Sucroalcooleira Paulista: Os Determinantes da Adoção das Tecnologias de Agricultura de Precisão

\subsection{Modelo estimado}

Os resultados (efeitos marginais, desvios padrões, testes e médias) do modelo lógite, em que a variável dependente foi se a empresa adota AP ou não, estão expressos na Tabela 2 . O teste de Wald, que avalia a hipótese nula de que todos os coeficientes angulares são simultaneamente iguais a zero, foi altamente significativo, indicando que a inclusão das variáveis explicativas é importante no modelo.

A análise dos resultados pode ser feita diretamente a partir do efeito marginal, que fornece o impacto de cada variável sobre a probabilidade de adoção da AP pela empresa. Os resultados indicaram que a maioria das variáveis explicativas é significativa ao nível de $1 \%$. Além disso, todas elas têm relação positiva com a probabilidade de a empresa adotar AP, o que está de acordo com os sinais esperados, com exceção da variável associação (AS), que, ao contrário do que se esperava, é negativo.

A origem do capital da empresa (OC) e do capital próprio (CP) foi positiva e significativa ${ }^{14}$. A variável origem do capital apresentou efeito marginal igual a 0,6145 , significando que o fato de a empresa ser de capital nacional provoca aumento na probabilidade de adoção da AP de 61,45 pontos percentuais em relação à empresa de capital estrangeiro. Tal resultado apoia a hipótese da literatura econômica investigada, de que o esforço inovativo das empresas de capital nacional é maior do que o das estrangeiras radicadas no Brasil, que concentram seus esforços inovativos nas matrizes em seus países de origem.

No tocante à adoção da $\mathrm{AP}$, qual a razão de a empresa adotar a $\mathrm{AP}$ no país de origem e não no Brasil, partindo do pressuposto de que existem vantagens no uso da tecnologia? Uma explicação plausível é a matéria-prima empregada, que pode diferir entre os países. Por exemplo: cultivar beterraba para a fabricação de açúcar no país de origem; e cana-de-açúcar, no Brasil. São realidades distintas que requerem também uso de tecnologias distintas, o que poderia explicar a não adoção da tecnologia no Brasil.

Outro fato que merece uma investigação mais aprofundada é que a maior parte das empresas estrangeiras entrou no Brasil por meio da aquisição de uma "planta" de capital nacional. Seria interessante analisar se a empresa estrangeira que adquiriu uma usina/destilaria brasileira que já estivesse adotando as

as variáveis do modelo estimado. Segundo Gujarati (2006), as correlações acima de 0,8 apontam possivelmente para um possível problema de multicolinearidade. Não foi encontrada nenhuma correlação acima de 0,8 nas variáveis presentes no modelo estimado neste trabalho.

${ }^{15}$ Os dados primários obtidos dos questionários corroboram esse fato: a área média das 


\section{Claudia Brito Silva Cirani

tecnologias de AP antes de sua aquisição, optaria pela continuidade ou não do uso da AP. Em um cenário de continuidade, esse fato atenuaria o resultado encontrado sobre a origem do capital. Então, esses fatores podem afetar a variável origem do capital, devendo esse resultado ser, então, interpretado com cuidado.

Pela Tabela 2, percebe-se que o capital próprio foi também importante para explicar o comportamento das empresas na propensão de adotar AP. Quando a empresa utiliza capital próprio, o lucro provocado pela venda desse bem é acrescentado ao capital, já convertido em meios de produção, promovendo sua capitalização, buscando estímulo para conceber novas combinações para o lucro. Os resultados mostraram que, quanto maior o percentual do valor dos dispêndios com as fontes próprias, em relação às fontes de financiamento de terceiros (privado e público), maior a chance de a empresa adotar AP, como esperado. De acordo com o efeito marginal estimado, por exemplo, o aumento de um ponto percentual na fonte própria implicaria aumento de 0,738 pontos percentuais na probabilidade de adoção da AP pela empresa.

Tabela 2. Efeitos marginais do modelo lógite das variáveis determinantes da adoção da AP na indústria sucroalcooleira - estado de São Paulo 2008

\begin{tabular}{lcccc}
\hline Variáveis & $\begin{array}{c}\text { Efeito } \\
\text { marginal }\end{array}$ & $\begin{array}{c}\text { Desvio } \\
\text { padrão }\end{array}$ & Testes Z & $\begin{array}{c}\text { Média das } \\
\text { variáveis }\end{array}$ \\
\hline Origem do capital (OC) & 0,614542 & 0,09448 & $6,50^{* *}$ & 0,908046 \\
Grupo (GR) & 0,532957 & 0,14548 & $3,66^{* *}$ & 0,574713 \\
Gestão da empresa (GE) & 0,274285 & 0,15985 & $1,72^{*}$ & 0,563218 \\
Área (AREA) & 0,000017 & 0,00001 & 1,37 & 18450,2 \\
Capital próprio (CP) & 0,007387 & 0,00286 & $2,58^{* *}$ & 68,7241 \\
Orientação exportadora (EX) & 0,423197 & 0,25178 & $1,68^{*}$ & 0,770115 \\
Associação (AS) & $-0,446011$ & 0,11127 & $-4,01^{* *}$ & 0,908046 \\
& & & & \\
Pseudo R & & & & \\
$\chi^{2}$ & $0,4682^{2 *}$ & & & \\
Observações & $31,91^{* *}$ & & & \\
\hline
\end{tabular}

Fonte: Dados da pesquisa.

${ }^{\text {a }}$ Em hectares.

${ }^{\mathrm{b}}$ Percentual do valor dos dispêndios com fontes próprias.

* $\mathrm{e}^{* *}$ representam significativos a $10 \%$ e $1 \%$, respectivamente. 
560 - Inovação na Indústria Sucroalcooleira Paulista: Os Determinantes da Adoção das Tecnologias de Agricultura de Precisão

É importante ressaltar que o custo de oportunidade deve ser considerado pelas usinas/destilarias. Esse custo pode ser definido como a taxa de rentabilidade que o capital pode ganhar na melhor alternativa de utilização, além do projeto (por exemplo, aplicar no mercado financeiro, ao invés de converter o capital em investimentos - máquinas e equipamentos para a implementação da $\mathrm{AP}$ - na empresa).

O modelo também mostra que, se a empresa é exportadora, a probabilidade de adoção da $\mathrm{AP}$ aumenta em 42,31 pontos percentuais. Esse resultado corrobora a hipótese de que a inserção de empresas nos mercados externos, os quais são mais exigentes, amplia a propensão delas a adotar novas tecnologias, a fim de enfrentar as pressões competitivas mais intensas no comércio internacional e as exigências dos padrões tecnológicos externos.

As variáveis referentes ao grupo (GR) e à gestão da empresa $(\mathrm{GE})$ também foram positivas e significativas. Constatou-se que o fato de a usina/destilaria fazer parte de um grupo empresarial aumenta a probabilidade de a mesma adotar $\mathrm{AP}$ em 53,29 pontos percentuais em relação à empresa independente. Esse resultado reforça, portanto, a hipótese levantada anteriormente de que a empresa utiliza-se de outras empresas do grupo como canal importante para difusão e conhecimento de novas tecnologias.

Além de o grupo ser uma variável importante para a explicação da propensão da empresa para adotar AP, notou-se também que o tipo de gestão da empresa é relativamente importante. Isto é, se ela possui gestão profissional, a probabilidade de adoção eleva-se em quase 30 pontos percentuais comparativamente às empresas de gestão familiar. Esse resultado é consistente com a ideia frequentemente difundida de que as empresas de gestão familiar são mais tradicionais e, portanto, mais resistentes a mudanças.

Um aspecto que chama a atenção é que, apesar de o coeficiente da área (AREA) ser positivo, indicando que um aumento na área da empresa aumenta a adoção da AP, o modelo não captou o efeito esperado para essa variável. Constatou-se, então, que a área não foi importante para explicar a decisão para a adoção. $\mathrm{O}$ fato de o modelo não ter captado o efeito esperado dessa variável pode sugerir que grande parte das usinas/destilarias da amostra possui escala suficiente para adotar $\mathrm{AP}^{15}$.

Outro fator interessante é referente ao sinal esperado da variável associação (AS). Esperava-se uma relação positiva entre associação e a

empresas que adotam AP foi de 22.103 ha, enquanto a das que não adotam foi de 13.739 ha. 
probabilidade de a empresa adotar essa tecnologia, indicando que a participação da empresa em associações do setor provocasse aumento na probabilidade da adoção. Isto é, esperava-se que o sinal do efeito marginal fosse positivo. No entanto, o sinal estimado foi negativo. Esse resultado parece revelar o quanto a associação não foi importante para as usinas/destilarias para poder adotar AP, revelando uma possível fraqueza das entidades ligadas ao setor sucroalcooleiro na difusão de novas tecnologias e, especialmente, no envolvimento com práticas deAP.

\section{Considerações finais}

Há evidências de que o setor sucroalcooleiro tem adotado as tecnologias de AP em larga escala. Porém, não existem ainda estudos sobre os condicionantes de sua adoção. Essa falta de pesquisas é consequência da escassez de dados e, também, porque é um campo de estudo ainda recente no País. Assim, este trabalho, cujo objetivo é a investigação de fatores que determinam a adoção e o uso das tecnologias de AP na indústria sucroalcooleira paulista, é justificado.

As análises são apresentadas em duas etapas. A primeira delas é a análise descritiva do nível de adoção e uso das tecnologias de AP nas usinas/destilarias paulistas, a partir dos dados primários obtidos por meio dos questionários. A segunda é a análise do modelo estimado, na busca por identificar os principais fatores responsáveis pela adoção da AP na indústria sucroalcooleira paulista.

Do universo de empresas que responderam ao questionário da pesquisa, verificou-se que $56 \%$ delas (49 empresas) adotam algum tipo de tecnologia de AP. Os resultados mostraram ainda que a tecnologia de AP, que tem sido mais utilizada nas usinas/destilarias paulistas, é a imagem de satélite (76\%). Em seguida, o piloto automático (39\%), as fotografias aéreas (33\%), a amostragem de solo em grade (com GPS) (31\%) e a tecnologia de aplicação em taxa variada (29\%) são as tecnologias que apresentaram maior grau de adoção. Entretanto, outras tecnologias não apresentaram taxa de adoção, como é o caso dos sensores e do mapeamento da condutividade elétrica do solo (ambas com 0\%).

No modelo econométrico estimado observou-se que a grande maioria das variáveis explicativas foi significativa e teve o sinal esperado, com exceção da variável área (AREA) e associação (AS). Os resultados mostraram que as variáveis origem do capital (OC), grupo (GR), exportação (EX), gestão da empresa (GE) e capital próprio (CP) tiveram um impacto positivo e estatisticamente significativo sobre a probabilidade de a empresa adotar AP. Destes, o que teve maior impacto 
562 - Inovação na Indústria Sucroalcooleira Paulista: Os Determinantes da Adoção das Tecnologias de Agricultura de Precisão

foi a origem do capital (OC), indicando que o fato de a empresa ser de capital nacional provoca aumento na probabilidade de sua adoção de 61,45 pontos percentuais em relação à empresa de capital estrangeiro. $\mathrm{O}$ coeficiente da variável binária para grupo (GR) também se mostrou bastante significativo, apresentando efeito marginal de 0,5329, ou seja, se a empresa faz parte de um grupo empresarial, a probabilidade de adoção aumenta em 53,29 pontos percentuais comparativamente à empresa independente.

O coeficiente da variável binária para exportação (EX) também se mostrou positivo e significativo, evidenciando que as empresas mais orientadas para o exterior via comércio internacional têm mais chances de adoção, o que estaria condizente com a visão de que a inserção da empresa no mercado internacional mais exigente força a adotar novas tecnologias em direção à maior competitividade e qualidade.

Os resultados mostraram ainda que a gestão da empresa (GE) foi positiva e significativa, revelando que o fato de a empresa possuir gestão profissional aumenta a probabilidade de adoção em quase 30 pontos percentuais em relação às empresas de propriedade familiar. O mesmo aconteceu com o capital próprio (CP), que também se mostrou positivo, como esperado, indicando que, à medida que aumenta a proporção de capital próprio em relação às demais fontes de financiamento, a probabilidade de adoção da AP se eleva em 0,738 pontos percentuais.

O fato de o modelo não ter captado o efeito esperado da variável área (AREA), apesar de manter o sinal positivo, pode ser explicado pela área média das empresas da amostra, que têm escala suficiente para adoção de AP. Portanto, a área da empresa não interfere na probabilidade de a empresa a adotar.

Outro resultado identificado neste trabalho é o sinal negativo da variável associação (AS), que não era esperado. O coeficiente negativo dessa variável remete à discussão sobre o papel fundamental de entidades como meio para difundir novas tecnologias e fortalecer processos de aprendizado e capacitação voltados para as empresas da cadeia sucroalcooleira.

É indiscutível que a adoção e o uso de tecnologias menos agressivas ao meio ambiente, destinadas a melhorar a produtividade e rentabilidade do solo - fator cada vez mais valorizado - se tornará ferramenta indispensável nos próximos anos, nas empresas agroindustriais brasileiras. Não há dúvida que, à medida que a AP começa a ser adotada em larga escala, as análises sobre o seu processo de adoção e uso passam a ser informação relevante para a formulação de políticas públicas direcionadas a estimular e apoiar seu uso. 
Quanto às ferramentas de políticas públicas para ampliar a difusão dessa tecnologia, a diminuição das taxas de juros e o melhor acesso ao crédito são as principais formas de alcançar esse objetivo. O elevado risco de projetos de adoção de novas tecnologias, aliado aos impactos positivos dessas atividades, mais do que justifica a formulação de ações governamentais nessa área. Entretanto, não basta apenas ter linhas de financiamento disponíveis. É preciso que essas linhas tenham custo baixo para compensar o elevado risco das atividades em questão.

Por fim, não se pode deixar de ressaltar que este trabalho refere-se à indústria sucroalcooleira paulista. Entretanto, é fundamental que sejam realizados outros levantamentos, em outros estados onde a tecnologia é adotada. Só assim será possível obter resultados mais efetivos, mesmo que não se chegue a conclusões e a generalizações. Nesse sentido, espera-se que este trabalho possa servir de material instigador que suscite a realização de muitos estudos, mais abrangentes, voltados para a compreensão do processo de adoção e uso da AP no Brasil.

\section{Referências Bibliográficas}

BAIO, F.H.R. Aplicação de A. P. no plantio. In: RIPOLI, T.C.C.; RIPOLI, M.L.C.; CASAGRANDI, D.V.; IDE, B.Y. Plantio de cana-de-açúcar: estado da arte. Piracicaba: T.C.C. Ripoli, 2006. cap. 4, p. 92-101.

BATTE, M.T.; ARNHOLT, M.W. Farmer evaluation of precision farming technologies. Journal of the ASFMRA, Denver, v. 65, n.1, p. 78-89, 2002. Disponível em: <http://www.asfmra.org/cms/pdf/journal/batte78_89.pdf>. Acesso em: 23 abr. 2008.

DE NEGRI, J.A.; SALERNO, M.S. Inovações, padrões tecnológicos e desempenho das firmas industriais brasileiras. Brasília: IPEA, 2005. $728 \mathrm{p}$.

ENGLISH, B.C.; ROBERTS, R.K.; LARSON, J.A. A logit analysis of precision farming technology adoption in Tennessee. Knoxville: The University of Tennessee Agricultural Experiment Station, Department of Agricultural Economics, 2000, p. 1-22 (Staff Paper 00-01, 2000). Disponível em: <http://economics.ag.utk.edu/pubs/farm/logit.pdf>. Acesso em: 25 abr. 2008. 
564 - Inovação na Indústria Sucroalcooleira Paulista: Os Determinantes da Adoção das Tecnologias de Agricultura de Precisão

GREENE, W. Econometric analysis. 5. ed. New Jersey: Prentice Hall, 2003. $1026 \mathrm{p}$.

GUJARATI, D.N. Econometria básica. 4. ed. Rio de Janeiro: Elsevier, 2006. $812 \mathrm{p}$.

HAYAMI, J.; RUTTAN, V.W. Desenvolvimento agrícola: teoria e experiências internacionais. Tradução de M.V. von Bulow e J.S.W. von Bulow. Brasília: EMBRAPA, 1988. $583 \mathrm{p}$.

HOFFMANN, R. Variável dependente binária: lógite e próbite. Série didática n. 1262, 2. ed. Piracicaba: ESALQ/USP, 2002. 27 p.

LUNDVALL, B.A. National systems of innovation: towards a theory of innovation and interactive learning. London: Pinter Publishers, 1992. 342 p.

MCBRIDE, W.D.; DABERKOW, S.G. Information and the adoption of precision farming technologies. Journal of Agribusiness, Athens, v. 21, n. 1, p. 21-38, 2003. Disponível em: <http://www.agecon.uga.edu/ jab/Library/S03-02.pdf>. Acesso em: 23 abr. 2008.

MOLIN, J.P. Agricultura de precisão: o gerenciamento da variabilidade. Piracicaba: o autor, 2001. 83 p.

NELSON, R.; WINTER, S. An evolutionary theory of economic change. Cambridge: Harvard University Press, 1982. 437 p.

ORGANIZAÇÃOPARACOOPERAÇÃOEDESENVOLVIMENTOECONÔMICO - OCDE. Manual de Oslo: proposta de diretrizes para coleta e interpretação de dados sobre inovação tecnológica. Rio de Janeiro, 1997. 136 p. Disponível em: <http://www.finep.gov.br/imprensa/sala_imprensa/manual_de_oslo.pdf.> . Acesso em: 25 abr. 2008.

SCHUMPETER, J. Teoria do desenvolvimento econômico. São Paulo: Abril Cultural, 1982.169 p. (Os economistas).

SEVIER, B.J.; LEE, W.S. Precision agriculture in citrus: a probit model analysis for technology adoption. In: American Society of Agricultural Engineers - ASAE/ Canadian Society of Agricultural Engineering - CSAE, 2004, Ontario. Proceedings... Ontario: ASAE/CSAE, 2004. p. 1-13. 
SWINTON, S.M.; LOWENBERG-DEBOER, J. Evaluating the profitability of site-specific farming. Journal of Production Agriculture, Madison, v. 11, n. 4, p. 439-446, 1998.

UNIÃO DA INDÚSTRIA DE CANA-DE-AÇÚCAR - UNICA. Açúcar e álcool: tecnologia sucroalcooleira. Disponível em: <http://www.portalunica.com.br/ multimedia/videocast/default.asp?mmdCode=E35AB87C-880A-4ACB-84D4436BCE2F29BF > Acesso em: 20 maio 2008a.

UNICA: dados e cotações: estatísticas. Disponível em: <http:// www.unica.com.br/dadosCotacao/estatistica/>. Acesso em: 30 out. 2008b. 